\title{
INIBIDORES DE PROTEASES DE HOSPEDEIROS NATIVOS E EXÓTICOS E SUA AÇÃO EM INTESTINOS DE LAGARTAS DE Thyrinteina leucoceraea ${ }^{1}$
}

\author{
Jeanne Scardini Marinho², Maria Goreti Almeida Oliveira ${ }^{3}$, Raul Narciso Carvalho Guedes ${ }^{4}$, Angelo Pallini $^{4}$
} e Claudinei Lima Oliveira ${ }^{2}$

\begin{abstract}
RESUMO - Os insetos podem causar perdas consideráveis aos seus hospedeiros, entretanto alguns deles habitam em plantas sem causar-lhes danos. Por exemplo, Thyrinteina leucoceraea, herbívoro da entomofauna brasileira, pode ser encontrado na goiabeira, hospedeiro nativo da família Myrtaceae, sem que cause danos severos a essa planta. Os Eucalyptus ssp., entretanto, são hospedeiros exóticos (também da família Myrtaceae) no Brasil, vindos da Austrália, os quais sofrem ataques das lagartas de T. leucoceraea, que se tornaram pragas severas dessas plantas. Sabe-se que as plantas podem se defender contra o ataque de herbívoros e que um dos seus mecanismos de defesa pode ser a produção de inibidores de proteases, que possuem a capacidade de diminuir o desenvolvimento dos insetos e podem levá-los à morte. Baseado no desempenho da lagarta de T. leucoceraea nesses dois hospedeiros e na possibilidade de defesa da planta, o objetivo deste trabalho foi verificar a produção de inibidores de proteases por plantas de eucalipto e de goiaba quando atacadas por essas lagartas, bem como observar a resposta bioquímica no intestino das lagartas a esses inibidores. Notou-se que as plantas de eucalipto produzem mais inibidores de proteases que as goiabeiras. O bom desenvolvimento de T. leucoceraea em plantas de eucalipto, apesar da alta concentração de inibidores de proteases, pode ser devido ao aumento da atividade enzimática nos intestinos das lagartas quando alimentadas com essa planta. Os dados evidenciaram que T. leucoceraea desenvolveu uma adaptação aos inibidores de proteases produzidos pelo eucalipto, por meio do aumento das atividades de serino-proteases e cisteíno-proteases.
\end{abstract}

Palavras-chave: Thyrinteina leucoceraea, plantas de eucalipto e de goiaba e adaptação.

\section{PROTEINASE INHIBITORS OF NOVEL AND NATIVE HOST PLANTS AND THEIR ACTION IN MIDGUT OF Thyrinteina leucoceraea CATERPILLARS}

\begin{abstract}
Insects may cause considerable losses to plants, but some insects inhabit plants without causing any damages. For example, Thyrinteina leucoceraea, found in the guava plants, and a native Myrtaceae family host, does not cause any serious damage. However, Eucalyptus ssp., novel hosts (also Myrtaceae) in Brazil and introduced from Australia, suffer attacks by T. leucoceraea, which became a severe pest of this plant. Plants can defend themselves against herbivores using proteinase inhibitors which reduce insect development and lead them to death. Thus, based on studies on the development of T. leucoceraea caterpillars on these two hosts and plant defense, this work aimed to verify the production of proteinase inhibitors by guava and eucalyptus plants upon T. leucoceraea attack, and to observe the biochemical response of the midgut of the caterpillars to these inhibitors. Eucalyptus plants produced more proteinase inhibitors than guava plants. The good development of $\mathbf{T}$. leucoceraea in eucalyptus plants despite the high concentration of proteinase inhibitors may be due to an increase of enzyme activity in the caterpillars' midgut. Our data suggest that T. leucoceraea developed an adaptation to the proteinase inhhibitor produced by eucalyptus plants, by increasing serine-proteinase and cys-proteinase activities.
\end{abstract}

Keywords: Thyrinteina leucoceraea, eucalyptus plants, guava plants and adaptation.

\footnotetext{
${ }^{1}$ Recebido em 01.05.2007 e aceito para publicação em 22.08.2008.

${ }^{2}$ Programa de Pós-Graduação em Entomologia da Universidade Federal de Viçosa (UFV). E-mail: <jescardini@gmail.com>.

${ }_{3}^{3}$ Departamento de Bioquímica e Biologia Molecular da UFV. E-mail: <malmeida@ufv.br>.

${ }^{4}$ Departamento de Biologia Animal da UFV. E-mail: <guedes@ufv.br>e <pallini@ufv.br>.
} 


\section{INTRODUÇÃO}

As plantas podem desenvolver mecanismos de defesa que diminuem o ataque de herbívoros. Essa defesa das plantas pode ser constitutiva ou induzida; ambas podem se expressar de formas direta e indireta e consistem de compostos químicos e estruturas morfológicas que prejudicam o inseto, podendo reduzir-lhes a sobrevivência, o desenvolvimento e a reprodução (KARBAN e BALDWIN, 1997). A defesa induzida consiste em mudanças morfológicas, fisiológicas e químicas como resposta ao ataque, que reduzem a qualidade do hospedeiro para os herbívoros e podem prejudicá-los (AGRAWAL, 1998; KARBAN e BALDWIN, 1997). A expressão de defesas diretas, em geral, resulta em redução da sobrevivência, reprodução ou desenvolvimento de herbívoros. As defesas indiretas resultam em aumento da predação e do parasitismo dos herbívoros (KARBAN e BALDWIN, 1997).

Os herbívoros podem suplantar essas defesas de seus hospedeiros. Por exemplo, as Myrtaceae nativas do Brasil, como a goiabeira, abrigam insetos nativos sem que estes causem danos severos a essas plantas, entretanto esses mesmos herbívoros atingem surtos populacionais em eucaliptos, outra Myrtaceae (ZANUNCIO et al., 1990).

Holtz et al. (2003ab) mostraram que lagartas do gênero Thyrinteina tiveram o desenvolvimento prejudicado quando criadas com folhas de goiabeira em comparação com as criadas com folhas de eucalipto, evidenciando que plantas de goiaba se defendem melhor contra esses insetos. Considerando que as plantas se defendem contra o ataque dos insetos, por que essas lagartas são mais afetadas pela defesa da goiabeira do que pela defesa do eucalipto?

As plantas do gênero Eucalyptus (Myrtaceae), proveniente da Austrália, são muito usadas para a produção de madeira no Brasil (ZANUNCIO et al., 1993). O cultivo de eucalipto é recente no país, no que se refere à adaptação de um novo gênero ou espécie em lugar diferente (ZANUNCIO et al., 1995). As plantas de eucalipto contêm alta concentração de compostos secundários como tanino, fenóis e óleos essenciais que podem desenvolver o papel de defesa contra ataque de herbívoros (ANJOS et al., 1986; BRAGANÇA et al., 1998). Entretanto, muitos lepidópteros (Thyrinteina leucoceraea e T. arnobia, por exemplo) de mirtáceas brasileiras (Psidium guajava, por exemplo) passaram a atacar as plantas de eucalipto, causando muitas perdas em cultivos do gênero Eucalyptus (ANJOS et al., 1986; ZANUNCIO et al., 1993; BRAGANÇA et al., 1998).

O melhor desenvolvimento dos herbívoros nativos em plantas de eucalipto comparadas com as de goiaba pode ser devido a um mecanismo de defesa mais eficiente contra esses insetos nas goiabeiras. Em relação à defesa química das plantas, elas podem produzir compostos conhecidos como inibidores de proteases (CARLINI e GROSSI-DE-SÁ, 2002). As plantas podem usar os inibidores de proteases como defesa direta contra os insetos, constitutiva ou induzida, inibindo as enzimas proteásicas nos intestinos de suas pragas (CARLINI e GROSSI-DE-SÁ, 2002; LAWRENCE e KOUNDAL, 2002). Assim, a inibição de proteases irá diminuir a biodisponibilidade de aminoácidos para a síntese de proteínas necessárias ao crescimento e desenvolvimento do inseto, acarretando, dessa forma, sua morte (HILDER et al., 1987; RYAN, 1990; VILA et al., 2005). Pilon et al. (2006) verificaram que lagartas alimentadas com uma dieta contendo inibidores de proteases tiveram desenvolvimento reduzido em relação às lagartas alimentadas com a mesma dieta sem o inibidor. Partindo desse fato, é possível que as goiabeiras produzam mais inibidores de proteases do que as plantas de eucalipto.

Assim, o objetivo deste trabalho foi verificar a presença de inibidores de proteases em folhas de goiabeira e de eucalipto, bem como estudar o efeito desses inibidores no intestino das lagartas de T. leucoceraea.

\section{MATERIAL E MÉTODOS}

\subsection{Obtenção das lagartas e das mudas}

As lagartas foram obtidas da criação massal mantida no Laboratório de Acarologia do Setor de Entomologia da Universidade Federal de Viçosa (Viçosa, Minas Gerais, Brasil) e criadas até o quinto ínstar larval para serem utilizadas no experimento.

As mudas de plantas de goiaba e de eucalipto foram padronizadas com aproximadamente $50 \mathrm{~cm}$ de altura e com histórico livre de aplicação de qualquer produto via foliar ou infestação de insetos.

\subsection{Montagem do experimento}

Para o experimento, 16 mudas de eucalipto e 16 de goiabeira foram colocadas em duas gaiolas $(1,0 \mathrm{x}$ 
0,75 x 0,70 m), uma para cada hospedeiro, sendo cada gaiola correspondente a um tratamento. Em cada muda foram colocadas três lagartas de quinto ínstar. Após $6,12,24$ e $48 \mathrm{~h}$, três plantas foram removidas de cada gaiola. As mudas retiradas não retornaram à gaiola e tiveram suas folhas recolhidas para obtenção do extrato foliar. As lagartas retiradas tiveram os intestinos extraídos para obtenção do extrato enzimático. Em cada horário de cada tratamento foram realizadas três repetições do extrato intestinal da lagarta (sendo utilizadas três lagartas em cada repetição) e do extrato foliar das mudas retiradas (uma muda por repetição).

\subsection{Obtenção dos extratos enzimático e foliar}

As lagartas foram dissecadas em $\mathrm{HCl}\left(10^{-3} \mathrm{M}\right) \mathrm{a}$ $4^{\circ} \mathrm{C}$. O extrato enzimático foi obtido através do rompimento celular resultante de nove ciclos de congelamento em nitrogênio líquido e descongelamento em banho-maria a $37^{\circ} \mathrm{C}$, conforme metodologia utilizada no Laboratório de Enzimologia, Bioquímica de Proteínas e Peptídeos - BIOAGRO/UFV. Após os ciclos, frações de $1,0 \mathrm{~mL}$ do extrato foram centrifugadas em tubos plásticos de $1,5 \mathrm{~mL}$ com tampas a $10.000 \mathrm{~g}$ por $30 \mathrm{~min}$ a $4{ }^{\circ} \mathrm{C}$. O sobrenadante contendo o material solúvel foi retirado e mantido a $-18^{\circ} \mathrm{C}$ para análises posteriores.

O preparo do extrato bruto foi realizado a $4{ }^{\circ} \mathrm{C}$, de acordo com o método descrito por Ohta et al. (1986). As folhas pesadas e imediatamente congeladas em nitrogênio líquido foram trituradas em almofariz. O pó obtido foi macerado em tampão fosfato de sódio 50 $\mathrm{mM}$, pH 6,5, na proporção de $1: 3(\mathrm{p} / \mathrm{v})$, e em seguida centrifugado a $17.200 \mathrm{~g}$ por $60 \mathrm{~min}$, a $4{ }^{\circ} \mathrm{C}$, segundo metodologia descrita por Batista et al. (2002). O sobrenadante foi armazenado a $18^{\circ} \mathrm{C}$ negativos, para posterior análise.

\subsection{Concentração de proteína}

A concentração de proteína foi obtida pelo método descrito por Bradford (1976), utilizando-se como padrão uma solução de $0,2 \mathrm{mg} / \mathrm{mL}$ de soroalbumina bovina (BSA).

\subsection{Atividade proteásica}

A atividade foi determinada usando-se azocaseína $2 \%(\mathrm{p} / \mathrm{v})$ como substrato e Tris- $\mathrm{HCl}(0,1 \mathrm{M}, \mathrm{pH} 8,0)$ a $37^{\circ} \mathrm{C}$ como tampão (TOMARELLI et al., 1949). Após 30 min, a atividade proteolítica foi interrompida com a adição de ácido tricloroacético $10 \%$ (v/v) e as amostras, centrifugadas para remover a proteína precipitada. A atividade do sobrenadante foi medida a $440 \mathrm{~nm}$. O experimento foi realizado em uma série de três repetições.

\subsection{Atividade estereásica de tripsina-like}

A atividade estereásica foi determinada usandose o substrato $\mathrm{N}$ - $\alpha$-p-tosil-L-arginina metiléster (LTAME, $0,1 \mathrm{mM})$ a $25^{\circ} \mathrm{C}$ em tampão Tris- $\mathrm{HCl}(0,1 \mathrm{M}$, $\mathrm{pH} 8,2$ ) contendo $20 \mathrm{mM} \mathrm{CaCl}_{2}$ (HUMMEL, 1959). A absorbância foi medida a $247 \mathrm{~nm}$ durante $2,5 \mathrm{~min}$, usandose coeficiente de extinção molar de $540 \mathrm{M}^{-1} \cdot \mathrm{cm}^{-1}$ para determinar a atividade das enzimas tripsina-like. Todas as medidas foram realizadas em triplicata.

\subsection{Atividade enzimática de cisteíno-proteases}

A atividade de cisteíno-proteases (cys-proteases) foi determinada com o uso de inibidores (adaptado de ERLANGER et al., 1961). Foram misturados 0,59 $\mathrm{mL}$ de tampão Tris- $\mathrm{HCl}(0,1 \mathrm{M}, \mathrm{pH} 8,0) ; 10 \mu \mathrm{L}$ de extrato (foliar ou do intestino); e $0,1 \mathrm{~mL}$ do inibidor benzamidina (10 mM). Após $15 \mathrm{~min}$ de incubação a $25^{\circ} \mathrm{C}, 0,5 \mathrm{~mL}$ do substrato $\mathrm{N}$ - $\alpha$-benzoil-L-argininina- $p$-nitroanilida (L-BApNA, 1,2 mM) foi adicionado. A velocidade foi monitorada a $410 \mathrm{~nm}$ durante $2,5 \mathrm{~min}$, usando-se o coeficiente de extinção molar de $8.800 \mathrm{M}^{-1} \cdot \mathrm{cm}^{-1}$ para determinar a atividade de cisteíno-proteases. Todas as medidas foram realizadas em triplicata.

\subsection{Inibição de proteases}

A presença de inibidores de proteases no extrato foliar e no extrato do intestino médio de T. leucoceraea foi determinada utilizando-se tripsina bovina. A atividade tríptica, na presença de inibidores, consistiu no seguinte procedimento analítico, para a análise do teste: $50 \mu \mathrm{L}$ do extrato; $500 \mu \mathrm{L}$ do tampão Tris- $\mathrm{HCl}(0,1 \mathrm{M}, \mathrm{pH} 8,2)$ contendo $20 \mathrm{mM}$ de cloreto de cálcio e $50 \mu \mathrm{L}$ da solução de tripsina $\left(4,7 \times 10^{-5} \mathrm{M}\right)$ foram adicionados a um tubo de ensaio. Para o controle da enzima foram adicionados, a outro tubo de ensaio, $550 \mu \mathrm{L}$ do tampão Tris-HCl $(0,1 \mathrm{M}, \mathrm{pH} 8,2)$ contendo $20 \mathrm{mM}$ de cloreto de cálcio e $50 \mu \mathrm{L}$ da solução de tripsina $\left(4,7 \times 10^{-5} \mathrm{M}\right)$. A mistura contida em ambos os tubos (teste e controle da enzima, respectivamente) foi incubada por $5 \mathrm{~min}$, à temperatura ambiente. Após o tempo de incubação, $500 \mu \mathrm{L}$ da mistura de incubação, do teste e do respectivo controle, foram retirados e adicionados a outro tubo com $500 \mu \mathrm{L}$ de Tris- $\mathrm{HCl}$ 0,1 M, pH 8,2, contendo $20 \mathrm{mM}$ de cloreto de cálcio e $500 \mu \mathrm{L}$ da solução de L-BApNA 1,2 mM. A absorbância da solução foi determinada a $410 \mathrm{~nm}$

R. Árvore, Viçosa-MG, v.32, n.6, p.1125-1132, 2008 
durante 2,5 min de reação. As análises foram feitas numa série de três repetições.

Os resultados foram convertidos em $\mathrm{mg}$ de tripsina inibida por grama de proteína, de acordo com a seguinte equação:

mg de tripsina inibida/grama de proteína $=\frac{A \times B}{C \times 1.000 \times P}$ em que:

A = absorbância a $410 \mathrm{~nm}$ do controle - absorbância a $410 \mathrm{~nm}$ da amostra;

$\mathrm{B}=$ diluição da amostra;

$\mathrm{P}=$ concentração, em $\mathrm{g} / \mathrm{mL}$, de proteína dos extratos; $\mathrm{e}$

$\mathrm{C}=$ fator de tripsina, ou seja, o produto da atuação de $1 \mu \mathrm{g}$ de tripsina ativa sobre o substrato L-BApNA dá uma leitura de absorbância em 410 nm de 0,019 (adaptado de KAKADE et al., 1970).

\subsection{Análise estatística}

As análises de variância com medidas repetidas no tempo foram realizadas utilizando o procedimento PROC ANOVA do SAS com a especificação PROFILE (SAS, 1989). Os pressupostos da análise de variância foram testados usando o procedimento PROC UNIVARIATE do SAS (SAS, 1989), e todos os dados tiveram que ser transformados em $\log 10(\mathrm{X}+1)$.

\section{RESULTADOS E DISCUSSÃO}

A concentração de inibidores de proteases medida pela inibição de serinoproteases decresceu com o aumento do período de infestação de lagartas nas folhas de goiabeira, mas não nas folhas de eucalipto, e foi significativamente maior nas folhas deste do que nas daquela (Figura 1, Wilks' Lambda $=0,000089 ; \mathrm{F}=171,63 ; \mathrm{df}_{\text {numerador }}=9 ; \mathrm{df}_{\text {denominador }}$ $=34.223 ; \mathrm{P}<0,0001)$. Os resultados evidenciaram que as plantas de eucalipto produziram mais inibidores de proteases (IPs) do que as plantas de goiaba quando ambas foram atacadas por T. leucoceraea (Figura 1). Portanto, permanece a questão: por que as plantas de eucalipto, mesmo produzindo mais IPs, são mais atacadas por essas lagartas do que as de goiaba? Tem sido postulado um mecanismo de defesa de plantas via produção de inibidores de proteases. Estes inibem proteases do intestino do inseto, o que compromete o seu crescimento e desenvolvimento, podendo levá-loà morte (FARMER e RYAN, 1992; PILON et al., 2006).

R. Árvore, Viçosa-MG, v.32, n.6, p.1125-1132, 2008

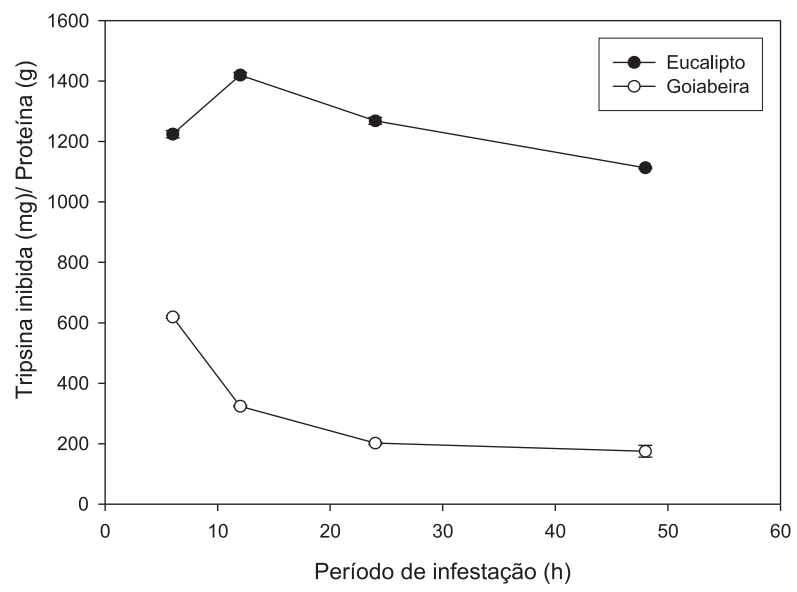

Figura 1 - Efeito do período de infestação de plantas de eucalipto e de goiaba por lagartas de T. leucoceraea na produção de inibidores de proteases no extrato foliar.

Figure 1 - The effect of the infestation period of eucalyptus and guava plants by caterpillars (T. leucoceraea) on proteinase inhibition in leaf extracts.

Possivelmente os inibidores de proteases produzidos pela goiabeira sejam moléculas mais adaptadas às proteases do intestino de T. leucoceraea, sendo, portanto, passíveis de certo grau de hidrólise tríptica como também possivelmente apresentem constante de inibição maior do que os inibidores produzidos pela planta de eucalipto. Para entender o sucesso ou o fracasso da interferência dos IPs no desenvolvimento de insetos herbívoros através de dieta artificial ou quando aplicados diretamente em plantas, muitos fatores devem ser considerados, como: a concentração do IP, o coeficiente de interação $(\mathrm{Ki}) \mathrm{com}$ as proteases, a estabilidade do IP no intestino do inseto, a presença de outros inibidores que possam inibir outras classes de proteases do intestino e a habilidade do inseto para se adaptar à inibição (JOGSMA e BOLTER, 1997). Além disso, fatores alimentares desempenham papel importante na severidade dos sintomas (BROADWAY e DUFFEY, 1986, 1988; MARKWICK et al., 1995).

Alguns insetos conseguem se adaptar a determinados compostos de defesa produzidos pelas plantas. Lagartas de Spodoptera frugiperda, por exemplo, são capazes de suplantar os efeitos deletérios de inibidores de proteases de plantas de soja em dieta artificial, possivelmente através de uma habilidade na produção de novas enzimas tripsina-like menos sensíveis aos inibidores produzidos pelas plantas e ingeridos pelos insetos e, também, através da síntese de outras classes de enzimas (PAULILLO et al., 2000; OLIVEIRA et al., 2005; XAVIER et al., 2005; PILON et al., 2006). 
Neste trabalho, lagartas alimentadas com folhas de eucalipto apresentaram maior concentração de protease total no intestino do que aquelas alimentadas com folhas de goiabeira (Wilks' Lambda $=0,081418$; $\mathrm{F}=6,85 ; \mathrm{df}_{\text {numerador }}=9 ; \mathrm{df}_{\text {denominador }}=34.223 ; \mathrm{P}<0,0001$, Figura 2). Esses dados indicam que o inseto possivelmente tenha-se adaptado à alta concentração de IPs produzidos pelas plantas de eucalipto, através da produção de novas proteases. A maior concentração de protease total no intestino de lagartas alimentadas com eucalipto pode ser devida ao aumento da atividade de serinoproteases, também observado nessas lagartas de forma mais acentuada do que naquelas alimentadas com folhas de goiabeira (Wilks' Lambda $=0,040132 ; \mathrm{F}=10,45$; $\mathrm{df}_{\text {numerador }}=9 ; \mathrm{df}_{\text {denominador }}=34.223 ; \mathrm{P}<0,0001 ;$ Figura 3$)$. Além disso, o extrato do intestino de lagartas de $T$. leucoceraea apresentou maior atividade de cisteínoproteases, indicando que possivelmente tenha ocorrido síntese dessas enzimas quando as lagartas foram alimentadas com folhas de eucalipto em relação às alimentadas com folhas de goiabeira (Wilks' Lambda $=0,065491 ; \mathrm{F}=7,85 ; \mathrm{df}_{\text {numerador }}=9 ; \mathrm{df}_{\text {denominador }}=34.223$; $\mathrm{P}<0,0001$, Figura 4), Essa pode ser uma resposta do inseto provavelmente como forma de adaptação aos IPs produzidos pelas plantas de eucalipto. Deve-se observar, entretanto, que a atividade de serino-proteases foi maior do que a de cisteíno-proteases nos extratos dos intestinos das lagartas de eucalipto e goiaba (Figuras 3 e 4), mostrando que serino-proteases são as principais enzimas proteolíticas produzidas nos intestinos dessas lagartas, o que está de acordo com estudos anteriores acerca de outras espécies da ordem Lepidoptera (PURCELL et al., 1992; TERRA e FERREIRA, 1994).

Apesar de apresentarem menor concentração de IPs do que o extrato foliar de eucalipto, as goiabeiras tiveram maior quantidade de proteína total (Wilks' Lambda $=0,012219 ; \mathrm{F}=19, .43 ; \mathrm{df}_{\text {numerador }}=9 ; \mathrm{df}_{\text {denominador }}$ $=34.223 ; \mathrm{P}<0,0001$, Figura 5). Os inibidores de proteases são importantes proteínas utilizadas na defesa das plantas contra os insetos (LAWRENCE e KOUNDAL, 2002), mas não são as únicas. Além disso, se não são hidrolisados pelas proteases, não estão contribuindo, de forma direta, para a biodisponibilidade de aminoácidos a serem utilizados para o crescimento e desenvolvimento do inseto. Outras moléculas protéicas também podem estar envolvidas no mecanismo de defesa da planta, tais como as lectinas, moléculas inativadoras de ribossomos dos tipos 1 e 2, inibidores de glico-hidrolases, arcelinas, quitinases e canatoxinas (CARLINI e GROSSI-DE-SÁ, 2002). Portanto, é possível que as plantas de goiaba utilizem outras moléculas protéicas para a defesa contra o ataque das lagartas, uma vez que elas apresentaram alta concentração de proteína nas folhas, maior que a observada nas folhas de eucalipto.

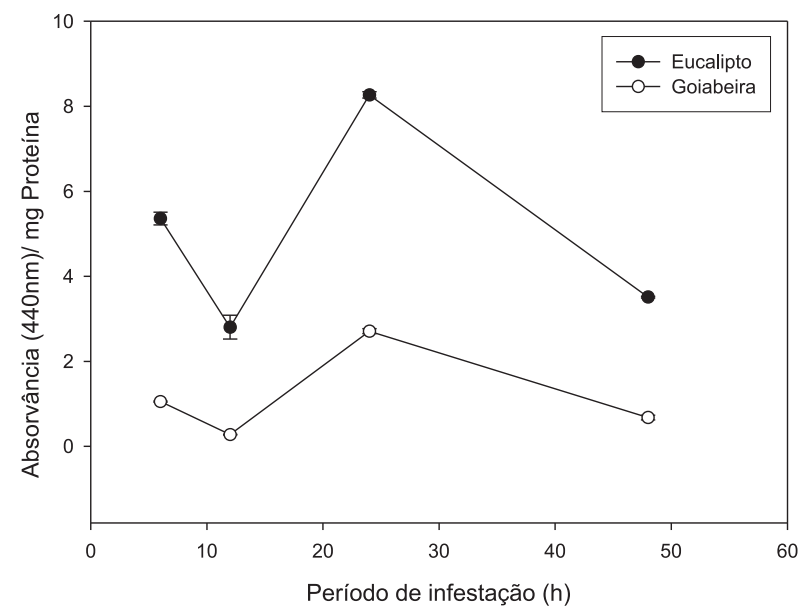

Figura 2 - Efeito do período de infestação de plantas de eucalipto e de goiaba por lagartas de $T$. leucoceraea sobre a atividade proteolítica no seu intestino.

Figure 2 - The effect of the infestation period of eucalyptus and guava plants by caterpillars (T. leucoceraea) on the proteolytic activity of these caterpillars.

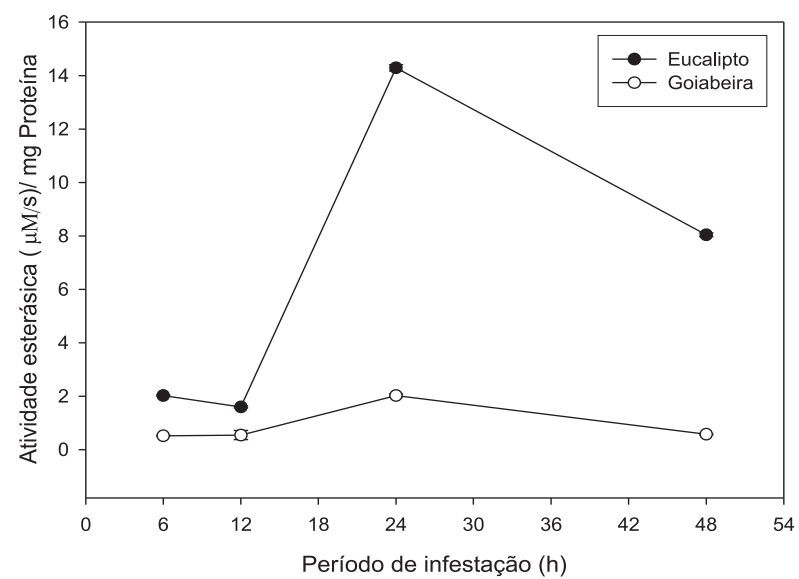

Figura 3 -Efeito do período de infestação de plantas de eucalipto e de goiaba por lagartas de T. leucoceraea sobre a atividade de enzimas tripsina-like no extrato intestinal.

Figure 3 - The effect of the infestation period of eucalyptus and guava plants by caterpillars (T. leucoceraea) on the activity of trypsin-like enzymes of these caterpillars.

R. Árvore, Viçosa-MG, v.32, n.6, p.1125-1132, 2008 


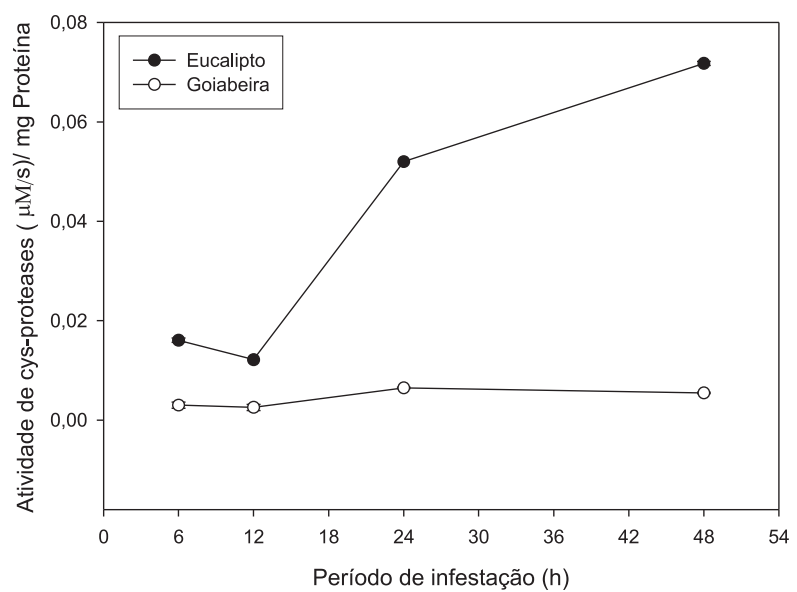

Figura 4 - Efeito do período de infestação de plantas de eucalipto e de goiaba por lagartas de $T$. leucoceraea sobre a atividade de cisteinoproteases no extrato intestinal.

Figure 4-The effect of the infestation period of eucalyptus and guava plants by caterpillars (T. leucoceraea) on the cis-proteinase activity of these caterpillars.

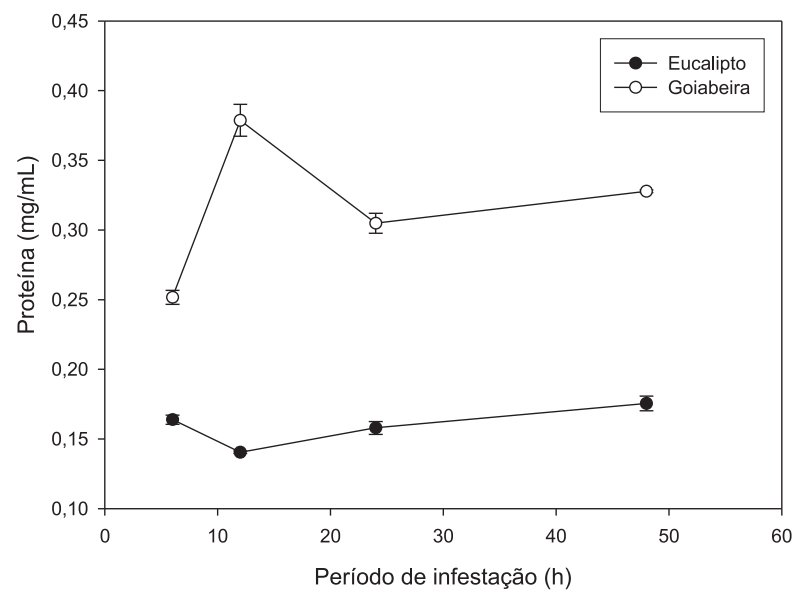

Figura 5 - Efeito do período de infestação de plantas de eucalipto e de goiaba por lagartas de T. leucoceraea sobre a concentração de proteína no extrato foliar.

Figure 5 - The effect of the infestation period of eucalyptus and guava plants by caterpillars (T. leucoceraea) on protein concentration in leaf extracts.

No processo de coevolução entre plantas e insetos, as plantas podem desenvolver mecanismos de defesa que diminuem o ataque dos herbívoros, as defesas diretas das plantas (KARBAN e BALDWIN, 1997; AGRAWAL e KARBAN, 2000; ARIMURA et al., 2005). Essa defesa pode ser induzida por um ataque prévio do herbívoro. Modificações fenotípicas em resposta à herbivoria podem ocorrer de diversas formas, através da produção de compostos tóxicos ou antinutritivos, alteração da composição de constituintes nutricionais ou protéicos, mudança na textura foliar e na densidade dos pêlos, espinhos ou tricomas etc. (KARBAN e BALDWIN, 1997). Essas mudanças no fenótipo das plantas podem torná-las resistentes ou suscetíveis a um posterior ataque de herbivoria. Entretanto, em resposta a esses mecanismos de defesa das plantas, outros para suplantá-la podem se desenvolver nos herbívoros (MAURÍCIO e RAUSHER, 1997). Essa superação por parte dos herbívoros às defesas das plantas pode ter ocorrido com as lagartas de $T$. leucoceraea nas plantas de eucalipto.

As plantas de eucalipto produzem mais inibidores de proteases do que as goiabeiras, mas são mais atacadas pelas lagartas de T. leucoceraea, que possivelmente se adaptou à defesa daquelas plantas através do aumento da produção de enzimas digestivas, tanto serino quanto cisteíno-proteases. As goiabeiras podem ter sido favorecidas durante a sua longa história de coexistência com as lagartas de T. leucocerae através da produção de IPs, que são mais eficientes contra o ataque desses herbívoros. Outros estudos devem ser realizados, a fim de investigar a ação, a composição e a eficiência dos IPs produzidos pelas goiabeiras, pois um melhor conhecimento desses compostos pode auxiliar o controle das lagartas de T. leucoceraea nas plantas de eucalipto.

\section{AGRADECIMENTOS}

À Fundação de Amparo à Pesquisa do Estado de Minas Gerais (FAPEMIG) e ao Conselho Nacional de Desenvolvimento Científico e Tecnológico (CNPq), pelo suporte financeiro.

\section{REFERÊNCIAS}

AGRAWAL, A. A. Induced response to herbivory and increased plant performance. Science, v.279, n.5354, p.1201-1202, 1998.

AGRAWAL, A. A.; KARBAN, R. Specificity of constitutive and induced resistance: pigment glands influence mites and caterpillars on cotton plants. Entomologia Experimentalis et Applicata, v.96, n.1, p.39-49, 2000.

ANJOS, N.; SANTOS, G. P.; ZANUNCIO, J. C. Pragas do eucalipto e seu controle. Informe Agropecuário, v.12, n.1, p.50-58, 1986. 
ARIMURA, C.; KOST, G.; BOLAND, W. Herbivoreinduced, indirect plant defences. Biochimica et Biophysica Acta, v.734, n.2, p.91-111, 2005.

BATISTA, R. B. et al. Caracterização bioquímica e cinética de lipoxigenases de plantas de soja submetidas à aplicação de ácidos graxos poliinsaturados. Pesquisa Agropecuária Brasileira, v.37, n.11, p.1517-1524, 2002.

BRADFORD, M. M. A rapid and sensitive method for the quantification of microgram quantities of proteins utilizing the principle of protein dye binding. Analytical

Biochemistry, v.72, n.1-2, p.248-254, 1976.

BRAGANÇA, M. A. L. et al. Effects of environmental heterogeneity on Lepidoptera and Hymenoptera populations in Eucalyptus plantations in Brazil. Forest Ecological Management, v.103, n.2/3, p.287-292, 1998.

BROADWAY, R. M.; DUFFEY, S. S. Plant proteinase inhibitors: Mechanism of action and effect on the growth and digestive physiology of larval Heliothis zea and Spodoptera exigua. Journal of Insect Physiology, v.32, n.10, p.827-833, 1986.

BROADWAY, R. M.; DUFFEY, S. S. The effect of plant protein quality on insect digestive physiology and the toxicity of plant proteinase inhibitors. Journal of Insect Physiology, v.34, n.12, p.1111-1117, 1988.

CARLINI, C. R.; GROSSI-DE-SÁ, M. F. Plant toxic proteins with insecticidal properties. A rewiew on their potentialities as bioinsecticides. Toxicon, v. 40, n.11, p.1515-1539, 2002.

ERLANGER, B. F.; KOKOWSKY, N.; COHEN, W. The preparation and properties of two new chromogenic substrates of trypsin. Archives of Biochemistry and Biophysics, v.95, p.271-278, 1961.

FARMER, E. E.; RYAN, C. A. Octadecanoid precursors of jasmonic acid activate the syntesis of wound-inducible proteinase inhibitors. The Plant Cell, v.4, n.2, p.129-134, 1992.

HILDER, V. A. et al. A novel mechanism of insect resistance engineered into tobacco. Nature, v.330, p.160-163, 1987.
HOLTZ, A. M. et al. Desempenho de Thyrinteina arnobia Stoll (Lepidoptera: Geometridae) em eucalipto e goiaba: o hospedeiro nativo não é um bom hospedeiro? Neotropical Entomology, v.32, n.3, p.427-431, 2003a.

HOLTZ, A. M. et al. Aspectos biológicos de Thyrinteina arnobia (Lep.: Geometridae) provenientes de lagartas criadas em folhas de Eucalyptus cloeziana ou de Psidium guajava sob condições de campo.

Revista Árvore, v.27, n.6, p.897-901, 2003b.

HUMMEL, B. C. W. A modified

spectrophotometric determination of chymiotrypsin, trypsin and trombin. Canadian Journal of Biochemistry Physiology. v.37, p.1393-1399, 1959

JONGSMA, M. A.; BOLTER, C. The adaptation of insect to plant protease inhibitors. Journal of Insect Physiology, v.43, n.10, p.885-896, 1997.

KAKADE, M. L.; SWENSON, D. H.; LIENER, I. E. Note on the determination of chymotrypsin and chymotrypsin inhibitor activity using casein. Analytical Biochemistry, v.33, n.2, p.255-258, 1970 .

KARBAN, R.; BALDWIN, I. T. Evidence for chewing insect-specific molecular events distinct from a general wound response in leaves. Plant Physiology, v.115, n.4, p.1299-1305, 1997.

LAWRENCE, P. K.; KOUNDAL, K. R. Plant protease inhibitors in control of phytophagous insects. Electronic Journal of Biotechnology, v.5, n.1, p.93-109, 2002.

MAURICIO, R.; RAUSHER, M. D. Experimental manipulation of putative selective agents provides evidence for the role of natural enemies in the evolution of plant defense. Evolution, v.51, n.5, p.1435-1444, 1997.

MARKWICK, N. P. et al. Effect of dietary protein and protease inhibitors on coding moth (Lepidoptera: Tortricidae). Journal of Economic Entomology, v.88, n.1, p.33-39, 1995.

OHTA, H. et al. Changes in lipoxygenase components of rice seeding during germination. Plant Cell Physiology, v.22, n.5, p.911-918, 1986.

R. Árvore, Viçosa-MG, v.32, n.6, p.1125-1132, 2008 
OLIVEIRA, M. G. A. et al. Partial purification and caracterization of digestive trypsin-like proteases from the velvet bean caterpillar, Anticarsia gemmatalis. Comparative Biochemistry and Physiology, v.140B, n.3, p.369-380, 2005.

PAULILlO, L. C. M. S. et al. Changes in midgut endopeptidase activity of Spodoptera frugiperda (Lepidoptera: Noctuidae) are responsible for adaptation to soybean proteinase inhibitors.

Journal of Economic Entomology, v.93, n.3, p.892-896, 2000.

PILON, A. M.; OLIVEIRA, M. G. A.; GUEDES, R. N. C. Protein digestibility, protease activity and postembryonic development of the velvetbean caterpillar (Anticarsia gemmatalis) exposed to the trypsininhibitor benzamidine. Pesticide Biochemistry and Physiology, v.86, n.1, p.23-29, 2006.

PURCELL, J. P.; GREENPLATE, J. P.; SAMMONS, R. D. Examination of midgut luminal proteinase activities in six economically important insects.

Insect Biochemistry and Molecular Biology, v.22, n.1, p.41-47, 1992.

RYAN, C. A. Genes for improving defences against insects and pathogens. Annuals Reviews Phytopathology, v.28, p.425-449, 1990.

TERRA, W. R.; FERREIRA, C. Insect digestive enzymes: properties, compartmentalization and function. Comparative Biochemistry and Physiology, v.109B, n.1, p.1-62, 1994.
TOMARELLI, R.M.; CHARNEY, J.; HARDING, M.L. The use of azoalbumin as a substrate in the colorimetric determination or peptic and tryptic activity. Journal of Laboratory and Clinical Medicine, v.34, p.428-433, 1949.

VILA, L. et al. Expression of the maize proteinase inhibitor (mip) gene in rice plants enhances resistance against the striped stem borer (Chilo suppressalis): effects on larval growth and insect gut proteinases. Plant Biotechnology Journal, v.3, p.187-202, 2005.

XAVIER, L. P. et al. Membrane-bound trypsin-like activity of midgut proteases from Anticarsia gemmatalis (Lepdoptera: Noctuidae). European Journal of Entomology (Ceske Budejovice), v.102, n.2, p.147-153, 2005.

ZANUNCIO, J. C. et al. Levantamento e flutuação populacional de lepidópteros associados à eucaliptocultura: Região de Belo Horizonte, Minas Gerais, junho de 1986 a maio de 1987 . Revista Árvore, v.14, n.1, p.35-44, 1990.

ZANUNCIO, J. C. et al. Manual de pragas em florestas. Lepidoptera desfolhadores de eucalipto: biologia, ecologia, e controle. Viçosa, MG: Folha de Viçosa, 1993. 140p.

ZANUNCIO, T. V. et al. Biologia de Euselasia higenirs (Lepidoptera; Rionidae) e seu consumo foliar em Eucalyptus urophylla. Revista Brasileira de Entomologia, v.36, n.3, p.487-492, 1995. 